\title{
Dionisio Areopagita y el giro teológico de la fenomenología
}

\author{
Carlos Arboleda-Mora*
}

Resumen: Este artículo estudia la posibilidad de que la fenomenología haya dado el giro teológico al haber buscado en Dionisio Areopagita una salida al problema de la ontoteología. Tanto Lévinas como Henry y Marion se acercaron al proceso de la mística dionisiana para encontrar un camino (la continua reducción), una ontología (el hombre como sujeto pasivo), y un encuentro con el fenómeno saturado (posibilidad y actualidad de la mística).

Palabras clave: Giro teológico, Dionisio Areopagita, ontoteología, Jean-Luc Marion, reducción.

Abstract: The article examines the possibility of a theological turn in phenomenology, which resorted to Dionysus the Areopagite for a solution to the problem of ontothology. Lévinas, Henry and Marion approach the process of Dionysian mysticism to discover a path (continuous reduction), an ontology (man as a passive subject) and an encounter with the saturated phenomenon (possibility and actuality of the mystic).

Key words: Theological turn, Dionysus Areopagita, ontotheology, Jean-Luc Marion, reduction.

Résumé: Cet article étudie la possibilité que la phénoménologie ait réalisé le tournant théologique car celle-ci chercha chez Dionisio une sortie au problème de l'ontothéologie. Levinas, Henry et Marion se rapproche du processus de la mystique dionysienne afin de trouver un chemin (la réduction continue), une ontologie (l'homme en tant que sujet passif) et une rencontre avec le phénomène saturé (possibilité et actualité de la mystique).

Mots-clés: Tournant théologique, Dionisio Areopagita, ontothéologie, Jean-Luc Marion, réduction. 


\section{Volver al neoplatonismo}

Desde la escolástica tardía se dio la separación entre filosofía y teología que habían estado estrechamente unidas en los siglos anteriores dentro del mundo cristiano. La filosofía era no sólo la esclava de la teología sino que también daba los medios para la expresión teológica y justificaba los procesos místicos de ascensión hacia Dios. La mística, o vía espiritual, se colocaba como el supremo conocimiento de Dios, como se puede ver en Dionisio Areopagita de modo paradigmático.

El sistema de Dionisio es una síntesis y una integración del neoplatonismo, especialmente de Proclo, con las enseñanzas del cristianismo. El pensamiento filosófico de Proclo es una reflexión sobre la henosis. El culmen de todo es el Uno. De éste, que es unidad trascendente, procede la multiplicidad de las cosas. Es una procesión hacia afuera de la simplicidad a la pluralidad de los seres. Estos tienen una pertenencia propia que los hace buscar de nuevo la unidad con el Uno. Hay un alma que busca el Uno, un intelecto (nous) que sirve de intermediario y el Uno que es la meta. "La unificación o la simplificación de sí es la condición de la unión con aquel que es Uno y simple. La superación del yo, la simplificación o unificación del yo y la unión con el origen, coinciden"1. Todo progreso hacia el Uno conlleva una simplificación del yo, es decir, el despojo de la multiplicidad del mundo externo. Hay un rechazo del exterior y un regreso al interior donde el alma se vuelve hacia el intelecto ${ }^{2}$. Así se llega a la unión con el Uno deseado. Este proceso de regreso al Uno es la clave del pensamiento de Proclo. El sistema

1 Y. Andia, Henosis: L'union à Dieu chez Denys l'Aréopagite., Leiden, E. J. Brill, 1996, p. 6.

2 Ibídem, p. 7. Cfr. P. Rorem, Pseudo-Dionysius: A Commentary on the Texts and an Introduction to Their Influence, Oxford, Oxford University Press, 1993. procleano influye en Dionisio Areopagita. Éste utiliza el título Uno para referirse a la divinidad (aunque obviamente al Dios cristiano). Este Dios es absolutamente trascendente, inexpresable, ser supraexistente, palabra más allá del discurso. La total trascendencia indica no sólo que está sobre la creación sino sobre la misma noción de grandeza. Es completamente otro. El Uno es la causa de toda existencia y trasciende toda existencia. Ese Uno está fuera del alcance de todo proceso racional. No hay palabras para agarrar el inexpresable Bien, el Uno, la fuente de toda unidad, ser supraexistente ${ }^{3}$.

La semejanza con Proclo es impresionan$\mathrm{te}^{4}$. Dionisio trata de quitar lo pagano, pero en lo demás es semejante. Es como una teologización de la filosofía procleana. Y aunque teologización, la obra de Dionisio es profundamente filosófica. La experiencia mística es una experiencia humana de tipo trascendente. No una experiencia sobre el mundo empírico sino sobre la realidad trascendente de la divinidad. Es el encuentro con la realidad última. El hombre es presionado a dejar atrás todo lo percibido (imágenes subordinadas) y entendido (desapego), el conocimiento intelectual llega a su límite y no puede ir más allá. Hay que enfocar una nueva manera de pensar y conocer, un método que permita progresar hacia la unión con Aquél que está más allá de todo ser y conocimiento ${ }^{5}$.

Continúa con una fuerte exhortación al apofatismo, un método que va más allá de lo catafático o del conocimiento afirmativo. Dionisio se da cuenta de que otros modos de con-

3 DN I.588B, I.589B-C. Pseudo Dionisio Areopagita, Obras completas: Los nombres de Dios. Jerarquía celeste. Jerarquía eclesiástica. Teología mística. Cartas varias, edición preparada por T. H. Martín, presentación de $\mathrm{O}$. González de Cardedal, traducido por H. Cid Blanco, Madrid, Biblioteca de Autores Cristianos, 2002.

4 G. Ritacco, "Los himnos theárquicos", Teología y Vida, Vol. XLIII, No. 003, 2002, pp. 350-376.

5 TM, I.1 (997B). 
templación han servido pero no llegan hasta el final. Todo lo afirmado en otros métodos debe ser negado ${ }^{6}$. La realidad última trasciende todo lo que puede ser afirmado y aún lo que puede ser negado ${ }^{7}$. El apofatismo permite ascender más allá del conocimiento simplemente humano. La filosofía, habiendo alcanzado su frontera, comienza un proceso de alejamiento para que el sujeto llegue al reino de la experiencia directa y total.

Los aspectos principales que aporta Dionisio son: en primer lugar, una concepción sobre la naturaleza de la realidad. El universo es una procesión y un regreso de la divinidad y a esa divinidad. Esa procesión tiene sus grados y su jerarquía. En el centro está Dios. De Dios no se puede decir nada. Es luz increada y creadora, y de ella participan todas las cosas. Teniendo su origen en la irradiación de la luz primera, la naturaleza es como una cascada o corriente de luz que desciende de la luz primera y se refleja en todos los seres creados. La creación es un acto de iluminación que jerárquica y progresivamente se derrama por todo el universo, y hay un retorno de grado en grado de todo el universo hacia su fuente. Las jerarquías (celestial, eclesiástica y legal) se subdividen a su vez en varios órdenes que están descritos en las obras de Dionisio. Cada orden no tiene poder por sí mismo sino que es un agente del poder de Dios, y como tal participa en el poder divino. Todos los órdenes vienen de Dios y a Él retornan. Esta estructura jerárquica constituye la naturaleza de la realidad (estructura ontológica) e indica cómo llegar al conocimiento de ese universo (estructura epistemológica) en un proceso de procesión y regreso. En la procesión, Dios está comprometido como autorrevelación, mientras que en el regreso los seres humanos están comprometidos como seres que vuelven al origen. A través de la participación en la emanación de la autorrevelación de Dios se demuestra que las jerarquías son naturalmente simbólicas. Como símbolos, las jerarquías representan el lugar de donde vienen y anagógicamente ascienden o nos ascienden hacia la próxima jerarquía. Gra-

6 MT, II (1025B).

7 MT, I.2 (1000B). cias a su participación de lo divino, el símbolo es también teofanía o manifestación divina que rodea a todas las criaturas. En las jerarquías está en forma de símbolo la presencia de lo divino sin ser lo divino.

En segundo lugar, un método para interpretar esa realidad. A través de una dialéctica positiva y negativa, Dionisio establece un método para interpretar los símbolos de la jerarquía habilitando el regreso o ascenso anagógico que es el método que permite ascender a través de la jerarquía. Este proceso comienza en lo positivo, es decir, en aquello que puede ser afirmado de Dios en los símbolos, y se va a un modo negativo de interpretación donde lo que ha sido previamente afirmado es negado. Entonces, cada símbolo indica así una semejanza y una desemejanza al mismo tiempo. La semejanza será afirmada y la desemejanza será negada. Esta dialéctica continúa así hasta el último estado del proceso. Método anagógico de afirmar y negar progresivamente. La interpretación de los símbolos corresponde a tres estadios de progreso del alma: la purgación de la materialidad de los símbolos, la iluminación de la significación de los símbolos y la perfección por el abandono de la significación en ascensión a la próxima jerarquía, a un símbolo más alto. Cada estadio está relacionado con la estructura epistemológica, de modo que la purgación es la remoción de la ignorancia, la iluminación es la recepción de nuevo conocimiento y la perfección es el abandono del conocimiento presente para lograr algo más alto ${ }^{8}$ Estos tres estadios se repiten a lo largo de cada jerarquía mientras se está ascendiendo.

Tercero, una metodología para llegar a la unión con lo divino. El paso final es el abandono de todos los conceptos interpretativos a través del no-conocer. El último estadio del movimiento anagógico lleva más allá de la dialéctica positiva-negativa por una negación de todo lo que ha sido negado. Esto coloca al hombre en estado de no conocimiento donde ocurre la experiencia de unión silenciosa con lo divino. La Teología mística provee una descripción de dicho

$8 \mathrm{CH} 3$; EH 5. 
estado: a medida que nos sumergimos en esas tinieblas que están más allá del intelecto, nos encontramos no simplemente sin palabras sino sin discurso, no conociendo 9 . Para describir lo que está más allá de las categorías del conocimiento humano, Dionisio usa el prefijo hiper que da énfasis a la naturaleza trascendente de lo divino.

Pero ese influjo dionisiano se fue perdiendo a medida que la teología se convirtió en teología de escuelas (escolástica), donde se daba primacía a la elaboración racional y se perdió el contacto con lo místico. En ese momento comenzó a hablarse de Dios desde la dogmática y no desde la experiencia, y los teólogos se interesaban más por la ortodoxia del concepto que por la realidad misma de Dios. Las críticas modernas al concepto de Dios provienen precisamente de esta separación entre la reflexión filosófico-teológica y la mística como contemplación del Ser. En el siglo XX, Heidegger considera que toda la obra filosófica desde Platón hasta Nietzsche ha sido una ontoteología, o sea la reducción del ser a ente y de Dios a sumo ente. Se oculta así el ser y aparece el ente. Esta ontoteología sería una concepción racional conceptual de Dios que oculta lo que es verdaderamente Dios. El término, tomado de Kant, permite a Heidegger inaugurar su crítica de la metafísica occidental y abre el camino para los antimetafísicos. En la historia de la filosofía occidental se han dado dos tipos de respuestas al problema de los seres: qué son en cuanto tales (ontología) y qué son en cuanto totalidad (teología). Esto es lo que Heidegger ha llamado el "carácter fundamentalmente ontoteológico de la metafísica".

La cuestión "¿Qué es un ser?" (o ¿qué es lo que es?), simultáneamente pregunta: ¿Cuál ser es el más alto (o supremo) ser y en qué sentido es el más alto ser? Ésta es la cuestión de Dios y de lo divino. Llamamos a este dominio, teología. Esta dualidad de la cuestión del ser de los seres puede ser unida bajo el título de ontoteología ${ }^{10}$.

9 MT 3

10 M. Heidegger, "Kant's Thesis about Being", traducción al inglés de T. E. Klein y W. E. Pohl en Southwestern Journal of Philosophy, Vol. 4, No. 3, 1973, pp. 7-33.Citado en I. Thomson, Heidegger on ontotheology, Cambridge, Cambridge University Press, 2005, p. 301.
El rol primario de la metafísica ha sido el establecimiento y el mantenimiento de un fundamento de los seres. El ser como presencia plena y definida conceptualmente que fundamentaba toda vida y toda afirmación de los entes es el proyecto histórico de la metafísica occidental, pero en ese proyecto histórico se confunde la universalidad del ente con su particularidad. Desconoce así la diferencia ontológica y se olvida del ser. La metafísica es la época del olvido del Ser, olvidar la diferencia entre el Ser y el ente. No se despliega la diferencia ontológica o se piensa esta diferencia desde el concepto de participación y representación. Esta representación es la presencia, no como presencia del Ser sino como presencia del ser del ente. El Ser es conceptualizado como ser del ente y se olvida el Ser. El destino del Ser es el olvido del Ser que es ser el ser de los entes, constituir los entes, unificar y diferenciar los entes y simultáneamente ocultarse tras los entes ya constituidos. El olvido del Ser, el olvido de la diferencia óntico-ontológica, impide y olvida indagar por la verdadera esencia del Ser.

El mismo Dios queda reducido a un ente, considerado dentro del horizonte de aparición del ser de los entes. Un ser atemporal y ahistórico que se da de una vez y para siempre, negando la historicidad y la multiplicidad. Se entiende más como ousia fija que como physis desbordante que emerge o como aletheia que se descubre y desvela. Se olvida el sentido de emergencia y descubrimiento, y se da preeminencia a la presencia y a la permanencia, en el sentido de lo duradero (ousia) ${ }^{11}$. ¿Hasta qué punto el Dios de la teología cristiana es el Dios de la metafísica fijista? Hay que hacer un análisis histórico crítico del uso de las categorías metafísicas en la teología. También hay que preguntarse si el Dios de la teología conceptual es el mismo de la Escritura. Aquí hay que investigar si las afirmaciones teológicas hechas bajo forma de conceptos corresponden a lo que expresa la Escritura. Santo Tomás ha sido quien más ampliamente ha usado la mezcla de metafísica y teología ${ }^{12}$. Es

11 Cfr. Thomson, Heidegger..., ob. cit., p. 318.

12 Aunque hay autores que hacen una lectura no ontoteológica de santo Tomás como Jean-Luc Marion. En Dieu sans l'être (1982) consideraba que Santo Tomás era uno de los padres de la ontoteología, pero ya en 
difícil armonizar el Dios de la Escritura con el simple, inmutable, actualizado, completamente existente Dios de la formulación conceptual dogmática. Se ve que mucho del contenido y las categorías teológicas conceptuales son más de la metafísica, que del Dios de la Escritura y más fijadas en la ousia que en la manifestación o en el don ${ }^{13}$.

De ayuda en esta discusión es la distinción heideggeriana entre Teología como hecho de fe y Teología como reflexión filosófica ${ }^{14}$. Ésta, como ontoteología, persigue el discurso sobre Dios y trata de definir los nombres divinos: primer motor, causa eficiente, ser necesario, "Dios como fundación última" (Leibniz), "Dios como moralidad" (Kant, Fichte, Nietzsche), "Dios como causa sui" (Descartes, Spinoza)... ${ }^{15}$. La ontoteología fija, explica y fundamenta. De allí dos de las críticas que se le hacen. Es fisicalista y violenta. En cuanto fisicalista produce la sensación de lo cristalizado, endurecido, que no cambia y con una existencia real cosmológica o conceptual al nivel del ente. En cuanto violenta, establece una sola verdad que ha de ser aceptada por todos y que se impone a todos, sin

el prefacio a la edición inglesa de God Without Being de 1991, sostiene que el esse tomista no es el ser criticado por Heidegger, pues el Dios tomista mantiene una distancia trascendente frente al orden de los entes: “...merece ser discutida y corregida la polémica que se refiere aquí, además de a Heidegger, a Tomás de Aquino. En efecto, la posición que adoptamos en 1982 ha variado claramente sobre este punto y, actualmente, sostenemos la aparente paradoja de que Tomás de Aquino no ha identificado la cuestión de Dios, ni la cuestión de sus nombres, con el ser al menos tal y como lo entiende la metafísica. Por ello, nos ha parecido útil retomar, en un anexo, el texto de una conferencia presentada primero en un coloquio organizado por el Instituto Católico de Toulouse (3-4 de junio de 1994) y aparecida posteriormente en la Revue thomiste (enero-marzo de 1995) bajo el título de 'Santo Tomás de Aquino y la onto-teo-logía'. No pretendemos acabar así con una polémica sin duda inevitable, sino tan sólo hacerla quizás más fecunda y mejor argumentada". J.-L. Marion, Dios sin el ser, traducción de F. Villegas Belmonte, D. Barreto González, J. Bassas Vila y E. Restrepo, Castellón de la Plana, Ellago, 2010, p. 13.

13 Cfr. S. D. Foutz, "Postmetaphysic Theology: a case study: Jean-Luc Marion", Quodlibet Journal, Vol. 1, No. 3, 1999. En línea: http://www. Quodlibet.net (consultado 13/05/2006). Christos Yannaras ya proponía que la lectura que hace Heidegger de la crisis de la metafísica era una forma de teología negativa. Y es la misma lectura de los fenomenólogos franceses, especialmente Marion. Esa destrucción de los ídolos conceptuales abre la posibilidad de pensar la trascendencia e inefabilidad de Dios retomando a Dionisio Areopagita. Cfr., C. Yannaras, De l'absence et de l'inconnaisance de Dieu d'apres les écrits aréopagitiques et Martin Heidegger, París, Editions du Cerf, 1971 y J.-L. Marion, El ídolo y la distancia, traducción de S. M. Pascual y N. Latrille, Salamanca, Sígueme, 1999.

14 Cfr. M. Heidegger, citado en J.-L. Marion, God Without Being, traducción al inglés de T. A. Carlson, Chicago, Chicago University Press, 1991, pp. 61-62.

15 Cfr. Foutz, "Postmetaphysic Theology...", ob. cit. posibilidad de más perspectivas. Así se da ocasión propicia a la crítica: ¿Por qué Dios pudo permitir esto o aquello? ¿Por qué Auschwitz? ¿Por qué Dios no castiga al injusto? ¿Por qué si el mundo es bueno y perfecto, suceden catástrofes? ¿Por qué los demás están equivocados? Pero hay más. ¿Hasta qué punto el Dios conceptual de la filosofía es el Dios de la experiencia de fe? La experiencia de los místicos no es expresada en conceptos de Dios sino en símbolos que dicen algo y no dicen todo de lo que sería la realidad absoluta, o la Realidad. La nueva filosofía francesa, especialmente, acepta las críticas a la ontoteología, pero también quiere ir más allá: buscar una filosofía (y luego una teología) sin referencia al Ser, en la línea de Dionisio Areopagita. Una filosofía que no sea idolátrica, estática y conceptual, sino que vaya al darse radical del fenómeno.

\section{Lévinas, Henry y Marion}

Lévinas se opone a las filosofías de la totalidad, es decir, de la reducción del otro al Mis$\mathrm{mo}^{16}$. La filosofía de la totalidad es una filosofía de violencia que no respeta al otro como tal, sino que lo considera un objeto de conocimiento, sometido al Todo ${ }^{17}$. Las filosofías tradicionales han sido violentas, pues tratan de analizar y objetivar toda la realidad. Crear una síntesis universal ontológica (sin pluralidad, diacronía o trascendencia) ha sido la tarea de la filosofía occidental. Lo humano como el sentido, el evento, el otro, la trascendencia, no entran en la agenda de la filosofía occidental. Por eso Lévinas trata de replantear esa filosofía dando prioridad a la ética como relación del mismo con el otro y a la trascendencia frente a la evidencia científica. Así la responsabilidad ética frente al otro se coloca desafiante frente a la Totalidad, sea ciencia, Estado o cualquier tipo de poder. Lo esencial no es el poder sino la relación con el otro. Lo humano no comienza con el conocimiento de tipo kantiano, sino en la relación. Esta relación parte

16 Cfr. E. Lévinas, Totalidad e infinito: ensayo sobre la totalidad, traducción de D. E. Guillot, Salamanca, Sígueme, 1999. En esta obra Lévinas plantea la relación cara a cara como base de toda ética.

17 Crf. ibídem, p. 67. La violencia es la reducción del otro al Mismo, es decir, no respetar la alteridad. 
del darse del otro, ese rostro que me interpela y que nunca podrá ser plenamente conocido. El yo sale de su enclaustramiento por la llamada del otro que se produce en la relación cara a cara, es decir, en la relación ética. Aquí está la filosofía primera: en la relación ética con el otro que me interpela, con el rostro que se me aparece $^{18}$. El otro es más originario a mi conciencia que la conciencia misma, la precede y se constituye en el dado (donnée) primordial. El otro es pre-intencional, existe antes de toda intencionalidad operante de la conciencia.

La relación con el otro es una relación social $^{19}$. Esto indica que la soberanía del yo se acaba para dar paso a la relación. Esta no se basa en el conocimiento como adecuación entre pensamiento y lo que se piensa. Su fundamento está en la relación, en la sociabilidad, donde lo infinito no se deja agarrar. Es en el deseo y no en el acceso ontológico cognoscitivo donde se puede dar el ingreso al otro: "Lo infinito no es objeto de un conocimiento, lo que lo reduciría a la medida de la mirada que contempla, sino lo deseable, lo que suscita el Deseo" ${ }^{\prime 2}$. El otro como Otro, infinito, trascendente, absolutamente otro, no es contenido en un concepto. Hay así una imposibilidad lógica de conceptualizar al otro, pero también hay una imposibilidad moral en cuanto que el otro tiene que ser respetado como Otro. No se trata de conocer al otro sino de mantener una relación ética con él. El otro no puede ser visto ${ }^{21}$, pues la mirada congelaría el ser del otro que ya sería abarcable y conceptuable ${ }^{22}$.

Lévinas elabora una alternativa a la ontoteología a partir de la relación ética con el otro. No es posible conocer a Dios sin un prójimo, es menester escuchar a Dios en la responsabilidad con el otro, como salida del ser impersonal. El método de Lévinas consiste en entender todo

18 Crf. ibídem, p. 20. Todas las ramas de la metafísica adquieren sentido a partir de esa filosofía primera.

19 Cfr. ibídem, p. 101.

20 Ibídem, p. 85.

21 Cfr. ibídem, p. 80.

22 Cfr. O. Bagüés, La relación cara a cara en el pensamiento de Lévinas, Barcelona, Universidad de Barcelona, 2003. En línea: http://www.lacavernadeplaton.com/articulosbis/levinas0203.htm (consultado 02/03/2009). problema (ontológico, trascendental, gnoseológico) bajo el ámbito de la ética, entendida como responsabilidad con el otro. La concepción ontoteológica llevó a las prácticas de dominación, miedo, violencia y control social, pues Dios era el ser impersonal, inmutable, lejano. Lévinas va proponiendo un Dios que está más allá del ser. Dios no es el ser impersonal. Dios es el Otro que me interpela, no un simple ser del que puedo hablar o al que puedo objetivar. La ontoteología permite una objetivación especulativa del Ser (Dios). La nueva propuesta permite una recepción del otro como fundamento de la ética: nuestra relación con otro consiste generalmente en querer comprenderle, pero la aparición del otro supera la comprensión. Esto porque el conocimiento del otro no nos afecta a partir de un concepto sino de su aparición ${ }^{23}$.

El Dios judeocristiano está en el orden de Otro que se aparece: “El Dios revelado de nuestra espiritualidad judeo-cristiana conserva todo el Infinito de su ausencia que está en el mismo orden personal. Él no se muestra más que por su huella [...]. Ir hacia él no es sino seguir esta huella que no es un signo, es ir hacia los Otros que están dentro de la huella" ${ }^{24}$. Cuando, en cambio, se trata de encerrarlo en la estructura del pensamiento, "la divinidad se disipa como las nubes que servían para describir su presencia" ${ }^{25}$.

Michel Henry, por su parte, apuesta por la inmanencia de la vida. Además del aparecer de los objetos, está el aparecer del sentimiento que es el aparecer de la vida. No sólo lo que se ve, sino lo que se siente. No está a gusto con la fenomenología de la exterioridad heideggeriana y opta por la interioridad (tomar la vida tal como cada uno la siente). La fenomenología henryana busca su fundamento dentro de la interioridad del sujeto a partir del sentimiento como dado absoluto. Debe hacerse una reducción que parte de la exterioridad para llegar a la inmanencia del sujeto auto-afectado. El Ser es

23 E. Lévinas, De Dios que viene a la idea, traducción de G. González y J. M. Ayuso Díez, Madrid, Caparrós, 1995, p. 103.

24 E. Lévinas, En découvrant l'existence avec Husserl et Heidegger, Paris, Vrin, 1982, p. 202.

25 Ibídem, p. 202. 
dado en esta interioridad y sólo ella puede recibir el fenómeno en su manifestación. Se trata de hacer un giro de la fenomenología: captar en su verdad las vivencias de la conciencia (impresiones, sentimientos, emociones). Estas se sienten pero no se ven. Por eso hay que sustituir una fenomenología del mundo por una fenomenología de la vida que sea ontología fenomenológica trascendental. La elaboración de ésta supone el abandono de la objetivación y de la intuición objetivante como vías de conocimiento, renunciar a la reducción de la filosofía a ciencia de las realidades ónticas. El horizonte de la manifestación no lo puede acoger la filosofía objetivante y por eso lo deja en lo indeterminable.

Hay que recorrer la vía del misterio, la morada del ser racionalmente indeterminable ${ }^{26}$. Ese misterio es la vida. Henry hace una fenomenología de la vida ${ }^{27}$. No se trata de partir de la trascendencia ni de la intencionalidad que acompaña esa trascendencia. Se trata de la inmanencia pura de la vida a ella misma, de la vida en cuanto se auto-afecta de manera original y sensible. Para esto se convierte en un filósofo del cuerpo. "La corporeidad como pathos inmediato que determina nuestro cuerpo a través y antes de que él se levante hacia el mundo" ${ }^{28}$. El cuerpo antes de toda trascendencia. Nuestro modo de existencia "es la subjetividad como esfera de existencia absoluta" ${ }^{29}$. Se hace necesario romper con la filosofía para la cual la fuente de toda realidad se encuentra realizada fuera de toda conciencia. No hay que buscar las condiciones de la experiencia en otra parte. "Todo el misterio de las nociones a priori desaparece delante de la antorcha de la experiencia interior ${ }^{\prime \prime 30}$.

La vida es toda impresión vivida, toda vivencia de conciencia. Ella reside en sí, en una inmanencia radical y sin distancia de sí misma.

\footnotetext{
26 Cfr. M. Henry, L'essence de la Manifestation, Paris, Presses Universitaires de France, 1963, p. 17.

27 Cfr. M. Henry, "Phénoménologie de la conscience, phénoménologie de la vie", en AA. VV., Sens et existence, en hommage à Paul Ricoeur, Paris, Seuil, 1975, pp. 138-151.

28 M. Henry, Philosophie et phénoménologie du corps, Paris, Presses Universitaires de France, 2003, p. V.

29 Ibídem, p. 34.

30 Ibídem, p. 42.
}

Es un acceso a la vida que no sigue la vía de la trascendencia, sino el camino de la interiorización. La vida, como pura inmanencia, es la fenomenalización originaria de toda realidad. La pura inmanencia aparece como un ser que no pretende ningún fundamento fuera de sí mismo. No es sino una pura autorreferencia que no conoce otro fenómeno más que su autoaparición. La Vida es experiencia absoluta y experiencia de lo absoluto. Es subjetividad pura. Vida e individualidad son inseparables pues la vida se engendra engendrando el yo, en el cual se muestra como vida ${ }^{31}$. La vida es invisible, sólo se siente. Ella se revela a sí misma (autorrevelación), es afectividad y no representación.

El pensamiento de Henry hace una fenomenología de la vida, inmanencia pura de la vida misma. La vida en cuanto se autoafecta de manera completamente original y sensible ${ }^{32}$. La vida es invisible. La vida es Dios. Constituye la esencia de Dios y la esencia del hombre como ser viviente: "La relación de la Vida al viviente es el tema central del cristianismo. Tal relación se llama desde el punto de vista de la vida generación, desde el punto de vista del viviente nacimiento. Es la Vida la que genera todo viviente concebible" ${ }^{\prime 33}$.

Sólo dentro de esta vida trinitaria, puede el hombre ser hombre. Sólo en el Cristo (la ipseidad original coengendrada por la Vida en su autoengendramiento) se da el nacimiento trascendental $^{34}$. La definición del hombre dentro del cristianismo es original. No es un logos aprisionado en el cuerpo, no es un animal racional, no es un yo trascendental, no es un ser físico-químico, ni siquiera un ser en el mundo. Es pura relación con Dios, un yo carnal viviente en y por la vida misma de Dios ${ }^{35}$. Esta concepción vuelve ridícula la concepción objetivista de la

\footnotetext{
31 Cfr. M. Henry, C'est moi la Vérité. Pour une philosophie du christianisme, Paris, Seuil, 1996, p. 151.

32 Cfr. ibídem, p. 51. Cfr., M. Henry, Généalogie de la psychanalyse, Paris, Presses Universitaires de France, 1985, p. 208.

33 Henry, C'est moi..., ob. cit., p. 68.

34 Cfr. Ibídem, p. 157.

35 Cfr. M. Henry, Incarnation. Une philosophie de la chair, Paris, Seuil, 2000, p. 244.
} 
ideología moderna y cientifista ${ }^{36}$. Esta vida es verdadera donación ${ }^{37}$. Ella se nos da y nos constituye $^{38}$. Henry trata de mostrar el carácter absolutamente fenomenológico del ser como afectividad ontológica fundante que se revela en la inmanencia ${ }^{39}$.

La "reducción radical" es empujar la reducción pura hasta que la donación se de ella misma:

Prolongando la reducción pura y llevándola a su término [...] reduce el aparecer mismo suspendiendo en él esta zona de luz que llamamos mundo y descubre aquello sin lo cual este horizonte de visibilización no se tornaría nunca visible: la autoafección de su exterioridad trascendental en el pathos sin rostro de la vida ${ }^{40}$.

Por su parte, Jean-Luc Marion considera que hay que superar el horizonte del objeto y el del ser. En la misma línea de Lévinas y Henry, busca abrirse a un nivel fenomenológico más originario que el nivel del ser. Marion trata esto en su libro Dieu sans l'etre ${ }^{41}$. Esta concepción de Dios sin el ser, la ha encontrado Marion en el neoplatonismo de Dionisio Areopagita ${ }^{42}$. El ídolo es la comprensión de Dios bajo conceptos, sean éstos antropomórficos o metafísicos. Pensar a Dios como ente supremo o como ente fundamento de la ética es idolátrico ${ }^{43}$. Pero aún pensar a Dios sobre el fondo del ser en su diferencia del ente es idolátrico. Dios sería pensado a partir de una precomprensión humana, la del ser.

¿Retroceder de la metafísica a suponer que llega el pensamiento dado al ser en tanto que ser, basta para liberar a Dios de la idolatría... o al

36 Cfr. Henry, C'est moi..., ob. cit., p 57.

37 Cfr. Henry, Incarnation..., ob. cit., p. 264.

38 Cfr. ibídem, p. 267.

39 Cfr. M. Lipsitz, "Michel Henry y la crítica del intuicionismo", en $A$ Parte Rei, No. 10. En línea: http://serbal.pntic.mec.es/ cmunoz11/henry.pdf (consultado 20/01/2005).

40 M. Henry, “Quatre principes de la Phénoménologie”, en Revue de Métaphysique et de Morale, 1, Paris, 1991, p. 18.

41 Cfr. J.-L. Marion, Dieu sans l'être, Paris, Presses Universitaires de France, 2002. Versión española : Dios sin el ser..., ob. cit. .

42 Cfr. J.-L. Marion, "La conversion de la volonté selon 'L'Action'”, en Revue Philosophique de la France et de l'Etranger, No. 177, 1987, pp. 33-46. J.-L. Marion, L'idole..., Paris, Grasset, 1977.

43 Cfr. Marion, Dios sin el ser..., ob. cit., pp. 48-49. contrario, la idolatría de la causa sui no reenvía a otra idolatría... más discreta... y por tanto, más amenazante? [...]. Más allá de la idolatría propia de la metafísica, opera otra idolatría propia del pensamiento del Ser en cuanto tal ${ }^{44}$.

La solución, para Marion, es pensar a Dios con el término de amor (agape). El amor se da y se da sin condiciones ${ }^{45}$. El donador se abandona completamente a la donación hasta coincidir donador y donación. Y darse completamente sin precomprensiones o comprensiones, es $\operatorname{amar}^{46}$. El amor excluye al ídolo, pues en el movimiento del darse, el sujeto no cubre al otro con su conceptualidad sino que se abandona totalmente a él, hasta dejarse determinar en esta donación. Ya no se trata de pensar a Dios desde la conceptualización humana, sino desde el donarse:

El amor no se da sino abandonándose, transgrediendo continuamente los límites del propio don, hasta trasplantarse fuera de sí. La consecuencia es que esta transferencia del amor fuera de sí mismo, sin fines ni límites, impide inmediatamente que se deje agarrar en una respuesta, en una representación, en un ídolo. Es típica de la esencia del amor -diffusivum suila capacidad de sumergir, así como una marea sumerge las murallas de un puerto extranjero, toda limitación, representativa o existencial del propio flujo; el amor excluye el ídolo, o mejor, lo incluye subvirtiéndolo. Puede también ser definido como el movimiento de una donación que, para avanzar sin condiciones, se impone una autocrítica permanente y sin reservas ${ }^{47}$.

Marion parte del estudio del principio fenomenológico. La fenomenología debe buscar el aparecer por encima de nuestra percepción subjetiva. Aparecer como mostrarse y no como demostrarse por parte del sujeto ${ }^{48}$. Pero es difícil, pues el conocimiento normalmente viene del sujeto. Se hace necesario un contramétodo, es decir, la paradoja de un método que

44 Ibídem, pp. 58 y 65

45 Cfr. ibídem, pp. 74-75.

46 Cfr. ibídem, p. 75.

47 Ibídem, pp. 74-75

48 Cfr. J.-L. Marion, Étant donné. Essai d'une phénoménologie de la donation, Paris, Presses Universitaires de France, 1997, p. 17. 
consiste precisamente en tomar la iniciativa de perder la iniciativa, siendo los fenómenos, los actores que se muestran y no el sujeto que los constituye. Constituir no equivale a construir o sintetizar, sino a reconocer el sentido en el hecho de que el fenómeno se da a sí mismo. Y la operación metodológica de la reducción consiste exclusivamente en quitar los obstáculos que impiden a la manifestación manifestarse ${ }^{49}$. Este giro metodológico lleva a la propuesta de un cuarto principio de la fenomenología: “Tanta reducción, tanta donación". Así se puede hablar de reducción a la inmanencia y permitir el darse efectivo de los fenómenos. Y la donación es la manifestación de por sí de los fenómenos sin permanecer nada de no dado, de trascendente, en ellos. Esta donación está filtrada por una reducción total. Esa donación constituye el principio último de la fenomenología $\mathrm{a}^{50}$. La donación hace patente la fenomenalidad del fenómeno en su totalidad saturante. La imposibilidad de expresarla en conceptos se debe a su exceso y no a su defecto ${ }^{51}$.

\section{El giro teológico de la fenomenología y el regreso a Dionisio}

La nueva fenomenología francesa ha tomado el camino de llevar la reducción al exceso, al punto de la donación total del fenómeno. Dominique Janicaud ha denominado este tipo de reflexión, "el giro teológico de la fenomenología francesa" 52 . De hecho, la fenomenología francesa ha venido tomando un matiz teológico en los últimos años con Lévinas y Marion principalmente, pero también con Courtine, Chrétien y Henry. El reclamo de Janicaud no es que la fenomenología esté cayendo en manos

49 Cfr. ibídem, pp. 16-17.

50 Cfr. G. Ferretti, Avvio alla lettura di Dato che. Saggio per una fenomenologia della donazione, di Jean-Luc Marion. En línea: http://www.unimc.it/ web_9900/prov_dip/Filosofia/Person/Ferretti/marion.htm (consultado $13 / 05 / 2006)$.

51 Este tema se puede ampliar en T. Jones, Apparent Darkness: Jean-Luc Marion's Retrieval of the Greek Apophatic Tradition, Cambridge (MA), Harvard University, 2008, p. 10.

52 D. Janicaud, Le tournant théologique de la phénoménologie française, Paris, Editions de l'éclat, 1991. Aquí citaremos la edición inglesa: D. Janicaud y J.-F. Courtine (eds.), Phenomenology and the 'Theological Turn': The French Debates (Perspectives in Continental Philosophy), traducción al inglés de B. G. Prusak, New York, Fordham University Press, 2000. confesionales, sino que ha sido invadida por preguntas e intereses teológicos. Categorías y conceptos como "apertura a lo invisible", "el Otro", el "don puro" o la "Arquirrevelación" muestran que hay un cambio de la fenomenología como método filosófico a la fenomenología teológica. ¿Qué es lo que pasa allí? Tradicionalmente, en la fenomenología se entendía que los fenómenos aparecen en el horizonte del sujeto y que de alguna manera ya había allí un logos. Éste sería el fondo sobre el cual los objetos se nos darían. Lévinas entiende que esto es imponer una violencia a los fenómenos y que éstos se dan inmediatamente al observador. El otro me trasciende de tal manera que no puedo afrontarlo sobre la base de un horizonte predeterminado. Marion, por su parte, dice que el hecho es que el fenómeno se da sin ningún yo que le proporcione las condiciones de posibilidad. Y Dios entra en los fenómenos que se dan absolutamente sin limitación alguna. Janicaud ve en esto una reflexión teológica, más propia de la metafísica especial que de la fenomenología $^{53}$. Dice que la neutralidad fenomenológica ha sido abandonada en un giro teológico que es demasiado obvio.

Janicaud critica a Lévinas considerando que su filosofía es un "descarrilamiento", pues cambia el método fenomenológico por la revelación, no hace reducción sino aceptación de la revelación del Otro. La filosofía de Lévinas es "un montaje metafísico-teológico [...] los dados están cargados y hechas las elecciones; la fe se levanta majestuosamente en el fondo [...] y el lector [...] se encuentra en la posición del catecúmeno que no puede sino penetrar las palabras sagradas y los altos dogmas" ${ }^{\prime \prime}$. Es intimidación, encantamiento, iniciación ${ }^{55}$.

Se está corrompiendo, según Janicaud, el futuro de la filosofía introduciendo el Dios bíblico en la fenomenología, pues la fenomenología y la teología hacen dos pensamientos distintos y no uno solo. Por eso propone medi-

53 Cfr. ibídem, pp. 63 y 68.

54 Ibídem, p. 27.

55 Cfr. ibídem 
tar, del lado teológico, una frase de Lutero: “La fe consiste en entregarse a la influencia de las cosas que no vemos", y otra del lado fenomenológico, tomada de Goethe: "Que no se vaya buscar nada detrás de los fenómenos: ellos mismos son la doctrina" ${ }^{\prime 56}$. Y concluye que hay que volver a la neutralidad metodológica de la fenomenología, sin las respuestas ya dadas y aceptadas de la teología. Janicaud hace su crítica desde un kantismo o husserlianismo que le lleva a descalificar muy rápidamente la obra de los franceses. Realmente no se trata de casar la fenomenología con una confesión religiosa en particular sino de ampliar la racionalidad filosófica a nuevos campos de la experiencia humana. Se trata de comenzar a pensar una especie de crítica de la razón mística no como una nueva región de la teología, sino como un desbordamiento de la fenomenología. La Teología, a partir de la experiencia del don, puede afrontar temas y modos insospechados superando una reflexión meramente especulativa de sus conceptos. Esta posición no metafísica es tomada de Dionisio: Dios, la divinidad, es sobreesencial y misteriosa. Ninguna palabra puede denominarlo adecuadamente ni decir qué es. No hay ningún esfuerzo humano que pueda captar a Dios. Él es pura manifestación, autorrevelación. Los conocimientos que tiene el hombre acerca de Dios tienen su origen en el mismo Dios. Los conceptos que se tienen de Dios son simbólicos, dicen y no dicen lo que es Dios. Él es tan superior que no se puede decir de él que es el ser o el bien pero trasciende aún estos términos.

La crítica de Janicaud presenta varios elementos para pensar. ¿Hasta qué punto la nueva fenomenología francesa ha tenido la "intención" de introducir a Dios en la fenomenología? ¿Frente al escepticismo actual no habrá un profundo deseo de fundamentación que haga girar la filosofía hacia lo Último ${ }^{57}$ Parece ser que si la metafísica ha olvidado su objeto, el Ser, por de-

56 Ibídem, p. 103.

57 Marion plantea tres formas de describir la relación entre filosofía y teología. Primero, la filosofía y la teología se relacionan como la caridad de Pascal con la metafísica de Descartes, del segundo y el tercer orden. Segundo, la fenomenología habla de la posibilidad del fenómeno y la teología de la historicidad del mismo. Tercero, el don de amor, fenomenológico y teológico, da coherencia al pensamiento dicarse a los entes, la fenomenología olvida el suyo, los entes, por dedicarse al Ser o un más allá del Ser. Realmente, una fenomenología radical es el camino de búsqueda iniciado por Heidegger y que puede llegar hasta el fenómeno total o saturado. Ahora, si la fenomenología quiere superar la metafísica, de todos modos se vislumbra en el fondo una intención teológica. Irse contra esa teologización no sería filosófico y sí es una prohibición que hace sospechar. Marion mismo dice que la crítica de las "posibilidades" de la fenomenología revela una perspectiva positivista incluida en el método de la fenomenología ${ }^{58}$. Pero ese parece no ser el problema, pues Janicaud encaja el golpe de Marion y afirma que eso sería desconocer la envergadura filosófica de la fenomenología y reducirla a una técnica de investigación empírica ${ }^{59}$. El verdadero problema es la búsqueda de lo invisible: lo invisible puro no se puede asir por la fenomenología. El salto en lo no objetivable haría imposible la reducción eidética y la hermenéutica misma ${ }^{60}$. Los fenomenólogos radicales dicen que lo invisible puede manifestarse en el horizonte mismo que él crea, como se da en la pintura, por ejemplo, de Kandinsky o de Marc Rothko. Es lo que pretende Jean-François Courtine con su deseo de llevar la fenomenología a su límite aplicando la frase de Heidegger "Más allá de la actualidad está la posibilidad"61. La fenomenología aprovecha esta posibilidad y obtiene éxito de ella evitando el idealismo absoluto o la misticología o la teosofía ${ }^{62}$. Esto requiere marchar más allá del fenómeno objetivo a la

sobre Dios. (Cfr. J.-L. Marion, "Metaphysics and Phenomenology: A Relief for Theology", en Critical Inquiry, Vol. 20, No. 4, 1994, pp. 572591). John Milbank critica fuertemente a Marion en esto, pues dice que es una reducción ilusoria y arbitraria y que no hace ningún sentido, pues quiere ser Barth y Heidegger al mismo tiempo. Cfr. J. Milbank, "Only Theology Overcomes Metaphysics", en The Word Made Strange: Theology, Language, Culture. Oxford, Wiley-Blackwell, 1997, p. 37.

58 Cfr. J.-L. Marion, "Métaphysique et Phénoménologie: une Réleve pour la théologie", L'avenir de la métaphysique, Coloquio organizado por la Facultad de Filosofía del Instituto Católico de Lyon y la Facultad de Teología del Instituto Católico de Toulouse, Bulletin de littérature ecclesiastique, No. 3, 1993, pp. 189-206, p. 199.

59 Cfr. para esta discusión a E. Gabellieri, “De la métaphysique à la phénomenologie: une relève?", en Revue Philosophique de Louvain, Vol. 94, No. 4, 1996, pp. 625-645.

60 Cfr. Ibídem, p. 629.

61 J.-F. Courtine, "Introduction: Phenomenology and Hermeneutics of Religion", en Janicaud. Phenomenology and the Theological Turn..., ob. cit., p. 122.

62 Cfr. ibídem, 125. 
misma esencia de la fenomenalidad que supera la reducción eidética y el sujeto constituyente. El acento se coloca, entonces, en una donación que se da a sí misma. La intuición directa de una fenomenalidad absoluta, como quiere Marion, es la síntesis del esfuerzo de la fenomenología radical.

¿Ha logrado esa fenomenología al exceso, destituir toda intencionalidad cuando habla de la aparición y de la donación? La posición de Marion tiene sus dificultades. ¿Cómo mantener la hermenéutica si todo se da por intuición plena? El acercamiento hermenéutico al fenómeno requiere lenguaje, cultura e historia y no parecen permitirse en el caso del fenómeno saturado. Esta es una de las dificultades grandes de esta fenomenología: si hay plena saturación y visión de lo invisible, es difícil hacer la hermenéutica de la manifestación. De ahí que Marion hable del fenómeno saturado y de su manifestación como una posibilidad fenomenológica, no como su realización, que correspondería al pensamiento teológico. La realización intuitiva del Ser Dado (Etant donné) demanda, más que un análisis fenomenológico, la experiencia de su donación que compete a la revelación teológica. Pero, en ese caso, ¿no se está fijando un límite a la fenomenología? De ahí que en Marion haya una tensión grande entre la manifestación total y el continuo esconderse del fenómeno saturado que lo lleva a buscar la universalidad de un método riguroso pero también la contextualización histórica de una interpretación infinita. Siempre habrá una hermenéutica de lo que se da totalmente pero también se oculta permanentemente y es leído según la contextualización del sujeto que tiene la experiencia de la saturación ${ }^{63}$.

Hay unos puntos comunes que quedan planteados con la relación Dionisio- fenomenología francesa:

- La posibilidad filosófica y la efectividad teológica de una experiencia de Dios.

63 Cfr. Jones, Apparent Darkness..., ob. cit., p. 10 y ss.
- La posibilidad de una crítica definitiva a la ontoteología desde la concepción autorrevelatoria del fenómeno saturado.

- La solución que aporta Dionisio a Heidegger y a los fenomenólogos al hablar de la simultaneidad de la manifestación y el ocultamiento.

- El carácter de la ética originaria que surge en el acto de revelación.

- $\quad$ El testigo de la manifestación, sujeto pasivo, elabora su experiencia con los símbolos que incluyen lenguaje, cultura, historia, pero que son siempre y constantemente hermenéutica del don ${ }^{64}$.

\section{Bibliografía}

Andia, Y., Henosis: L'union à Dieu chez Denys l'Aréopagite, Leiden, E. J. Brill, 1996.

Bagüés, O., La relación cara a cara en el pensamiento de Lévinas, Universidad de Barcelona, 2003. En línea: http://www.lacavernadeplaton. com/articulosbis/levinas0203.htm (consultado 02/03/2009).

Coakley, S. \& Stang, Ch., Re-thinking Dionysus the Areopagite, Oxford, Wiley-Blackwell, 2009.

Courtine, J.-F., "Introduction: Phenomenology and Hermeneutics of Religion", en D. Janicaud y J.-F. Courtine (eds.), Phenomenology and the Theological Turn. The French Debate (Perspectives in Continental Philosophy), traducción al inglés de B. G. Prusak, New York, Fordham University Press, 2000.

Ferretti, G., Avvio alla lettura di Dato che. Saggio per una fenomenologia della donazione, di Jean-Luc Marion. En línea: http://www. unimc.it/web_9900/prov_dip/Filosofia/Person/ Ferretti/marion.htm (consultado 13/05/2006).

Foutz, S. D., "Postmetaphysic Theology: a case study: Jean-Luc Marion", Quodlibet Journal,

64 Cfr. ibídem. Cfr. también S. Coakley y Ch. Stang, Re-thinking Dionysus the Areopagite, Oxford, Wiley-Blackwell, 2009. 
Vol 1, No. 3, 1999. En línea: http://www.Quodlibet.net (consultado 13/05/2006).

Gabellieri, E., “De la métaphysique à la phénomenologie: une 'relève'?", Revue Philosophique de Louvain, Vol. 94, No. 4, 1996, pp. 625-645.

Heidegger, M., "Kant's Thesis about Being", traducción al inglés de T. E. Klein y W. E. Pohl, Southwestern Journal of Philosophy, Vol. 4, No. 3, 1973, pp. 7-33.

Henry, M., L'essence de la manifestation, Paris, Presses Universitaires de France, 1963.

Henry, M., "Phénoménologie de la conscience, phénoménologie de la vie", AA. VV. Sens et existence, en hommage à Paul Ricoeur, Paris, Seuil, 1975, pp. 138-151.

Henry, M., Généalogie de la psychanalyse, Paris, Presses Universitaires de France , 1985.

Henry, M., "Quatre principes de la Phénoménologie", Revue de Métaphysique et de Morale, 1, Paris, 1991.

Henry, M., C'est moi la Vérité. Pour une philosophie du christianisme, Paris, Seuil, 1996.

Henry, M., Incarnation. Une philosophie de la chair, Paris, Seuil, 2000.

Henry, M., Philosophie et phénoménologie du corps, Paris, Presses Universitaires de France, 2003.

Janicaud, D., Le tournant théologique de la phénoménologie française, Paris, Editions de l'éclat, 1991. Versión inglesa: D. Janicaud y J.F. Courtine (eds.), Phenomenology and the 'Theological Turn': The French Debates (Perspectives in Continental Philosophy), traducción al inglés de B. G. Prusak, New York, Fordham University Press, 2000.

Jones, T., Apparent Darkness: Jean-Luc Marion's Retrieval of the Greek Apophatic Tradition, Cambridge (MA), Harvard University Press, 2008.
Lévinas, E., En découvrant l'existence avec Husserl et Heidegger, Paris, Vrin, 1982.

Lévinas, E., De Dios que viene a la idea, traducción de G. González y J. M. Ayuso Díez, Madrid, Caparrós, 1995.

Lévinas, E., Totalidad e infinito: ensayo sobre la totalidad, traducción de D. E. Guillot, Salamanca, Sígueme, 1999.

Lipsitz, M., “Michel Henry y la crítica del intuicionismo", A Parte Rei, No. 10. En línea: http://serbal.pntic.mec.es/ cmunoz11/henry. pdf (consultado 20/01/2005).

Marion, J.-L., "La conversion de la volonté selon 'L'Action'", Revue Philosophique de la France et de l'Etranger, No. 177, Vol. 1, 1987, pp. 33-46.

J.-L. Marion, God Without Being, traducción al inglés de T. A. Carlson, Chicago, Chicago University Press, 1991.

Marion, J.-L., "Métaphysique et Phénoménologie: une Réleve pour la théologie", en L'avenir de la métaphysique, Coloquio organizado por la Facultad de Filosofía del Instituto Católico de Lyon y la Facultad de Teología del Instituto Católico de Toulouse, Bulletin de littérature ecclesiastique, No. 3, 1993, pp. 189-206.

Marion, J.-L., "Metaphysics and Phenomenology: A Relief for Theology", Critical Inquiry, Vol. 20, No. 4, 1994, pp. 572-591.

Marion, J.-L., Étant donné. Essai d'une phénoménologie de la donation, Paris, Presses Universitaires de France, 1997.

Marion, J.-L., El ídolo y la distancia, traducción de S. M. Pascual y N. Latrille, Salamanca, Sígueme, 1999.

Marion, J.-L., Dios sin el ser, traducción de F. Villegas Belmonte, D. Barreto González, J. 
Dionisio Areopagita y el giro teológico de la fenomenología

Bassas Vila y E. Restrepo, Castellón de la Plana, Ellago, 2010.

Milbank, J., “Only Theology Overcomes Metaphysics", The Word Made Strange: Theology, Language, Culture, Oxford, Wiley-Blackwell, 1997. Pseudo Dionisio Areopagita, Obras completas: Los nombres de Dios. Jerarquía celeste. Jerarquía eclesiástica. Teología mística. Cartas varias, edición preparada por T. H. Martín, presentación de O. González de Cardedal, traducido por H. Cid Blanco, Madrid, Biblioteca de Autores Cristianos, 2002.
Ritacco de G., G. L., “Los himnos theárquicos", Teología y Vida, Vol. XLIII, No. 003, 2002, pp. 350-376.

Rorem, P., Pseudo-Dionysius: A Commentary on the Texts and an Introduction to Their Influence, Oxford, Oxford University Press, 1993.

Thomson, I., Heidegger on ontotheology, Cambridge, Cambridge University Press, 2005.

Yannaras, C., De l'absence et de l'inconnaisance de Dieu d'apres les écrits aréopagitiques et Martin Heidegger, Paris, Editions du Cerf, 1971. 
